\title{
Cultura Escolar: quadro conceitual e possibilidades de pesquisa
}

\section{School Culture: conceptual framework and research possibilities}

\author{
Fabiany de Cássia Tavares Silva*
}

\section{RESUMO}

\begin{abstract}
Os trabalhos sobre cultura escolar surgiram nos anos de 1980, mas a idéia de uma cultura escolar se fortaleceu nos anos de 1990, apresentando atualmente diferenciadas tendências investigativas. Este texto, portanto, esboça uma leitura inicial do quadro conceitual em estudo e das possibilidades de pesquisa na/pela cultura escolar.

Palavras-chave: Escola; cultura escolar; pesquisas em educação.
\end{abstract}

\begin{abstract}
The works on school culture appeared in the eighties, but the idea of a school culture strengthened in the nineties, presenting now differentiated investigative tendencies. This text, therefore, it sketches an initial reading of the conceptual picture in study and of the possibilities of research in/on the school culture.

Key-words: School; school culture; research in education.
\end{abstract}

A escola tem se tornado um objeto de estudo cada vez mais freqüente nas pesquisas desenvolvidas no país, contando com os mais diferentes

* Professora e pesquisadora da Linha de Pesquisa Escola, Cultura e Disciplinas Escolares do Programa de Pós-Graduação em Educação da Universidade Federal de Mato Grosso do Sul. 
enfoques de análise. Da História à Sociologia, da política educacional à prática pedagógica, cada uma dessas abordagens tem servido para colocála no centro das pesquisas educacionais.

A despeito dessas diferentes abordagens, um elemento está sempre presente quando o objeto de estudo é a escola, qual seja o reconhecimento da existência de uma cultura própria dessa instituição. Cultura que a conforma de uma maneira muito particular, com uma prática social própria e única. Ainda que os primeiros trabalhos tenham surgido nos anos 1980, a idéia de uma cultura escolar se fortaleceu nos anos 1990, apresentando atualmente diferenciadas tendências investigativas.

Diante disso, esse texto procura, em dois momentos distintos porém interconectados, dar conta dos princípios explicativos da relação escola e cultura escolar. Na primeira parte, expõe e analisa as articulações entre a História e a Sociologia no delineamento da cultura escolar, discernindo sobre os desafios com que elas se confrontam. Posteriormente, tenta mapear, ainda que superficialmente, algumas pautas para a pesquisa na/da/em cultura escolar, a partir dos princípios explicativos anteriormente delineados.

\section{Escola e cultura escolar: princípios explicativos}

Podemos dizer que existem inúmeras características que aproximam os comportamentos das escolas, bem como as investigações sobre ela, e há uma infinidade de outras que os/as diferenciam. No entanto, parece não haver inconvenientes em considerar a escola como uma instituição com cultura própria. Os principais elementos que desenhariam essa cultura seriam os atores (famílias, professores, gestores e alunos), os discursos e as linguagens (modos de conversação e comunicação), as instituições (organização escolar e o sistema educativo) e as práticas (pautas de comportamento que chegam a se consolidar durante um tempo).

Para Chervel (1988), a escola fornece à sociedade uma cultura constituída de duas partes: os programas oficiais, que explicitam sua finalidade educativa, e os resultados efetivos da ação da escola, os quais, no entanto, não estão inscritos nessa finalidade. Dito de outro modo, esse autor entende a cultura escolar como cultura adquirida na escola e encontra nela não somente seu modo de difusão, mas também sua origem. 
Tendo em vista essa definição, a escola tem uma função social básica, que vai além de prestar serviços educativos. Logo, não pode ser entendida como uma organização social, pois, essa figura burocrática está calcada na necessidade de gerir seu espaço e tempos particulares, o que, obviamente, contradiz as premissas que instituem a função social da escola, bem como o seu entendimento como um mundo social instituído de uma cultura própria.

O modo como a escola vem se organizando tem reforçado mecanismos geradores de adaptação e dominação. São esses mecanismos que certamente informam os processos pedagógicos, os organizativos, de gestão e de tomada de decisões no interior da escola, os quais vão além da legislação ou das recomendações feitas pela(s) entidade(s) mantenedora(s) e/ou pelo poder público. Assim, a escola, principal instituição da sociedade, responsável pela educação formal dos indivíduos, difere grandemente de outras organizações sociais.

A estrutura organizacional da escola não está sustentada apenas por um plano racional determinado pela burocracia. A escola é uma totalidade mais ampla, "compreendendo não apenas as relações ordenadas conscientemente, mas, ainda, todas as que derivam de sua existência enquanto grupo social" (CANDIDO, 1964, p. 107).

Sendo a escola, portanto, uma instituição da sociedade, ela é base para o conceito de sociedade moderna de que a humanidade dispõe atualmente, ou mais, a escola é "elemento fundante" para o espírito de modernidade, "um dos principais motores de triunfo da modernidade" (PINEAU, 1999, p. 39).

O que se está buscando apontar é que "a vida interna da escola (...) reelabora, segundo a sua dinâmica interna, as normas, valores, práticas comunitárias, dando-lhes uma coloração nova, mas nem por isso alheia ao encadeamento geral da sociedade" (CANDIDO, 1964, p. 111 e 128).

A organização e a estrutura de funcionamento e, portanto, de tomada de decisões no cotidiano escolar é peculiar, pois as escolas são instituições especiais e diferentes das organizações sociais, conforme afirma Nóvoa:

As escolas são instituições de um tipo muito particular, que não podem ser pensadas como qualquer fábrica ou oficina: a educação não tolera a simplificação do humano (...) que a cultura da racionalidade empresarial sempre transporta (NóVOA, 1998, p. 16). 
A cultura perpassa todas as ações do cotidiano escolar, seja na influência sobre os seus ritos ou sobre a sua linguagem, seja na determinação das suas formas de organização e de gestão, seja na constituição dos sistemas curriculares.

Viñao Frago lembra que a cultura escolar tem sido entendida como uma das "caixas pretas" da historiografia educacional e, no conceito de cultura escolar vê os

\begin{abstract}
modos de pensar e atuar que proporcionam a seus componentes estratégias e pautas para desenvolver-se tanto nas aulas como fora delas - no resto do recinto escolar e no mundo acadêmico - e integrar-se na vida cotidiana das mesmas (VIÑAO FRAGO, 2000a, p. 100).
\end{abstract}

A função da cultura escolar não seria promover uma incorporação de valores outros que não os objetivos escolares, ou mesmo de servir de ferramentas para a inculcação de valores. Pelo menos não são apenas essas as resultantes promovidas pela cultura escolar.

Viñao Frago concebe a cultura escolar como aquele conjunto de práticas, normas, idéias e procedimentos que se expressam em modos de fazer e pensar o cotidiano da escola e,

esses modos de fazer e de pensar - mentalidades, atitudes, rituais, mitos, discursos, ações - amplamente compartilhados, assumidos, não postos em questão e interiorizados, servem a uns e a outros para desempenhar suas tarefas diárias, entender o mundo acadêmico-educativo e fazer frente tanto às mudanças ou reformas como às exigências de outros membros da instituição, de outros grupos e, em especial, dos reformadores, gestores e inspetores (VIÑAO FRAGO, 2000a, p. 100).

Os indivíduos e suas práticas são basilares para o entendimento da cultura escolar, particularmente no que se refere à formação desses indivíduos, à sua seleção e ao desenvolvimento de sua carreira acadêmica. Dessa forma, os discursos, as formas de comunicação e as linguagens presentes no cotidiano escolar, constituem um aspecto fundamental de sua cultura. 
A escola tem sua cultura estabelecida, não sendo o sistema educacional diferente, isto é, também tem uma cultura institucionalizada a qual se expressa como aquele conjunto de

idéias, pautas e práticas relativamente consolidadas, como modo de hábitos. Os aspectos organizativos e institucionais contribuem (...) a conformar uns ou outros modos de pensar e atuar e, por sua vez, estes modos conformam as instituições num outro sentido (VIÑAO FRAGO, 1998, p. 169).

Observamos, então, a escola como uma instituição ímpar, que se estrutura sobre processos, normas, valores, significados, rituais, formas de pensamento, constituidores da própria cultura, que não é monolítica, nem estática, nem repetível.

É esse conjunto de características do cotidiano escolar que Forquin denomina de "Cultura da Escola". Para ele cultura é descrita enquanto um

mundo humanamente construído, mundo das instituições e dos signos no qual, desde a origem, se banha o indivíduo humano, tão somente por ser humano, e que constitui como que sua segunda matriz (FORQUIN, 1993, p. 168).

Em contraposição ao conceito de "Cultura da Escola", Forquin apresenta a "Cultura Escolar" como sendo aquele conjunto de saberes que, uma vez organizado, didatizado, compõe a base de conhecimentos sobre a qual trabalham professores e alunos. E nessa idéia está pressuposta uma seleção prévia de elementos da cultura humana, científica ou popular, erudita ou de massas.

Seriam esses elementos estruturais determinantes nos processos pedagógicos, organizativos, de gestão e de tomada de decisões no interior da escola, responsáveis pela instituição daquilo que Forquin (1993) chama de "mundo social" da escola, ou seja, o conjunto de "características de vida próprias, seus ritmos e ritos, sua linguagem, seu imaginário, seus modos 
próprios de regulação e de transgressão, seu regime próprio de produção e de gestão de símbolos" (FORQuin, 1993, p. 167).

Em Julia vamos encontrar a cultura escolar, dentro de uma abordagem histórica, como sendo uma mescla de normas e práticas, aquelas "que definem conhecimentos a ensinar e condutas a inculcar" e como um conjunto "que permite a transmissão desses conhecimentos e a incorporação de comportamentos" (2001, p. 2).

Em estudo sobre a cultura escolar como objeto da historiografia esse autor estabelece que a escola tem uma história que não é muito diferente da história de outras instituições da sociedade, como as instituições judiciais ou as militares. A cultura escolar, para ele, evidencia que a escola não é somente um lugar de transmissão de conhecimentos, mas é, ao mesmo tempo e talvez principalmente, um lugar de "inculcação de comportamentos e de habitus" (JuLIA, 2001, p. 14).

A lógica de inculcação que tem lugar na escola encontra resistência, lembra o autor, na cultura dos estudantes e da localidade ao redor da instituição, pois atualmente, antigamente e sempre "todos sabem que os professores não conhecem tudo o que se passa nos pátios de recreio, que existe, há séculos, um folclore obsceno das crianças" (JuLiA, 2001, p. 30).

A necessidade de conformação dos objetivos educacionais aos limites apresentados pela sociedade, em cada período da história, também tem impacto decisivo no estabelecimento da cultura escolar, pois ela é uma "cultura conforme, e seria necessário traçar, a cada período, os limites que traçam a fronteira do possível e do impossível" (JULIA, 2001, p. 25).

Seja cultura escolar ou cultura da escola, esses conceitos acabam evidenciando praticamente a mesma coisa, isto é, a escola é uma instituição da sociedade, que possui suas próprias formas de ação e de razão, construídas no decorrer da sua história, tomando por base os confrontos e conflitos oriundos do choque entre as determinações externas a ela e as suas tradições, as quais se refletem na sua organização e gestão, nas suas práticas mais elementares e cotidianas, nas salas de aula e nos pátios e corredores, em todo e qualquer tempo, segmentado, fracionado ou não.

Em Bourdieu e Passeron (1992), por exemplo, encontramos a afirmação de que o papel da escola é a produção e reprodução das condições institucionais para a reprodução cultural e para a reprodução social. Em outras palavras, a escola tem desenvolvido um padrão cultural, não apenas de repetição de comportamentos, mas de desenvolvimento mesmo de raciocínios para a solução dos diferentes problemas e para a convivência. 
Como "força formadora de hábitos", a escola provê aos que têm estado submetidos direta ou indiretamente à sua influência, não tanto de esquemas de pensamento particulares ou particularizados, senão desta disposição geral, geradora de esquemas particulares suscetíveis de serem aplicados em campos diferentes de pensamento e de ação, que se pode chamar de habitus culto (BOURDIEU, 1977, p. 25).

Parece que a escola conforma os indivíduos dotando-os "de um sistema de esquemas inconscientes que constituem sua cultura" (BOURDIEU, 1977, p. 26), isto é, uma cultura fundada em uma infinidade de práticas adaptadas a situações sempre renovadas, sem nunca se constituir em princípios explícitos.

No entanto, essa mesma cultura não é simples reprodutora, tão pouco refratária a mudanças, pois ela tem sua própria identidade construída entre o que escutam, o que lêem, o que já sabem e acreditam ideologicamente os indivíduos.

Williams, em seu reconhecido estudo sobre a cultura, apresenta mais elementos para a compreensão da cultura escolar, ou seja, conceitos mais relevantes sobre a reprodução cultural e a educação.

Devemos, pois, estar sempre preparados para falar em produção e reprodução e não apenas em reprodução. Mesmo tendo dado total valor a tudo quanto se possa descrever razoavelmente como réplica, em atividades culturais e sociais mais gerais, e tendo reconhecido a reprodução sistemática de certas formas profundas, ainda assim devemos insistir em que as ordens sociais e as ordens culturais devem ser encaradas como se fazendo ativamente: ativa e continuadamente, ou podem muito rapidamente desmoronar (WILLIAMS, 1992, p. 198).

Isso posto, mesmo reconhecendo a contribuição dos estudos que demonstram o caráter reprodutor na educação, Williams vê a necessidade de associá-la às suas características produtoras. Entende ainda a cultura como um sistema de significações, muito embora afirme que um sistema de significações, per se, não explica a organização social, mesmo porque há muitos outros sistemas para além dele: “(...) é sempre necessário ser capaz de distinguir sistemas econômicos, sistemas políticos e sistemas geracionais 
(de parentesco e de família), e ser capaz de discuti-los em seus próprios termos" (williams, 1992, p. 206).

Assim, nem toda produção cultural é uma produção ideológica, ou pelo menos, não deve ser vista assim, mesmo que a generalização dos conceitos de ideologia e de cultura permita essa aproximação: "Dizer que toda prática cultural é necessidade 'ideológica' não quer dizer nada mais (...) senão que toda prática é significativa" (williams, 1992, p. 28).

Essa idéia aponta para o entendimento da cultura como um sistema de significações realizado, voltado a abrir "espaço para o estudo de instituições, práticas e obras manifestamente significativas", mas não apenas isso: também para, "por meio dessa ênfase, estimular o estudo das relações entre essas e outras instituições, práticas e obras" (williams, 1992, p. 207208).

Parece ser a sociologia da cultura, proposta pelo autor, o veículo para se estudar os processos sociais, inclusive os denominados de ideologia, advindos de toda a produção cultural, pois

... é certo, como mostraram Bourdieu (1977) e outros, que há relações fundamentais e necessárias entre a versão seletiva [da educação] e as relações sociais predominantes em vigor. (...) Mas há, então, dois problemas: que pode haver (...) tipos significativos de desigualdade e de assimetria, ou (...) graus diversos de autonomia relativa; e que também é um fato observável dos sistemas educacionais (...) o de que eles mudam tanto internamente quanto em suas relações gerais com outros sistemas. A metáfora da "reprodução", se forçada em demasia, pode dissimular os processos essenciais de autonomia relativa e de mudança, mesmo enquanto insista de maneira conveniente em um caráter geral e intrínseco (WILLIAMS, 1992, p. 184).

Portanto, o significado do termo cultura tem se mostrado importante diante da necessidade de entendimento dos processos escolares históricos e atuais. A compreensão da cultura enquanto práxis, o significado de cultura como conjunto de práticas que conferem determinados significados aos lugares, aos indivíduos e aos grupos, inscreve-se no propósito de construir possibilidades de investigações histórico-educativas.

Nesse sentido, a cultura escolar é tanto o conjunto de saberes presentes nas determinações dos mitos, dos comportamentos, das tradições, das 
inovações e das relações sociais. Por outro lado, pode ser interpretada como uma variável ideológica/científica dependente da cultura geral.

Para essa interpretação, os terrenos de produção da Sociologia, História e História da Educação têm sido reconhecidamente um bom lugar para se pensar e dar novo significado a algumas pautas teórico-metodológicas, tais como: o tempo escolar, o espaço escolar, o currículo, os manuais, as autobiografias, as memórias, os diários, os aportes metodológicos, etc.

\section{Cultura Escolar: pautas para a pesquisa}

Sendo historicamente tributária de uma relação privilegiada com as áreas científicas da História e da Sociologia, a investigação da cultura escolar tem vindo progressivamente a constituir-se num espaço complexo que procura articular, entre outros aspectos, a cultura e a escola, o individual com o social, além de gerir a complexidade das relações entre as exigências da investigação e as exigências da intervenção.

Tal formato faz da investigação educacional um campo privilegiado para a renovação teórica e metodológica dos contextos epistemológicos, contextos organizacionais e contextos disciplinares, o que acaba por contribuir para que as escolas se reapropriem do sentido de suas práticas. Assim, vale a pena proceder a uma análise, mesmo que preliminar, das instâncias e das lógicas de difusão da produção de objetos de pesquisa da/ na/em cultura escolar.

Viñao Frago (2000), ao analisar os tempos e os espaços escolares como objetos históricos, propõe uma pergunta: por que esses temas estão presentes nas agendas dos pesquisadores da educação e por que meios? Para responder, destaca os percursos do Movimento Higienista do final do século XIX e início do XX, a história do currículo e das disciplinas escolares como elementos centrais para o estudo desses temas, bem como da configuração da cultura escolar, relacionada ao funcionamento interno da escola.

Tal destaque apresenta efeitos conceituais e metodológicos de pesquisa, uma vez que desnaturaliza a escola, a normalidade dos conceitos, produzindo novas perspectivas para as fontes disponíveis, recompondo significados. O tempo e o espaço escolar têm sido, então, concebidos essen- 
cialmente como uma das práticas que auxiliaria na operação desses efeitos. Para Viñao Frago (1998), o tempo e o espaço são, respectivamente, conceituados como:

primeiramente, um tempo pessoal, institucional e organizativo. Por outra parte tem sido entendido, desde essa dupla perspectiva, um dos instrumentos mais poderosos para generalizar e apresentar como natural e única, em nossas sociedades, uma concepção e vivência do tempo como algo mensurável, fragmentado, seqüenciado, linear e objetivo que traz implícita uma visão de meta e futuro (VIÑAO FRAGO, 1998, p. 19).

... nem um 'contenedor', nem um 'cenário', mas sim uma espécie de discurso que institui em sua materialidade um sistema de valores,... uns marcos para o aprendizado sensorial e motor e toda uma semiótica que cobre diferentes símbolos estéticos, culturais e, ainda, ideológicos. E, em suma, como a cultura escolar, da qual forma parte, 'uma forma silenciosa de ensino'. Qualquer mudança em sua disposição, como lugar ou território modifica sua natureza cultural e educativa (VIÑAO FRAGO, 1998, p.69).

As possibilidades, que nos parece generalizarem-se nesses conceitos, consistem em pluralizar a investigação do tempo e do espaço exigindo uma atualização contínua de observação da formação dos fenômenos educativos, no decorrer das mudanças dadas no cruzamento das esferas cultural, escolar e econômica. Para essa observação entendemos imprescindível a consciência da historicidade desse cruzamento, dos processos em que se apóiam, da manifestação do real e dos resultados a que, num dado momento, dá corpo.

Assim, supomos que para apreendermos o ritmo das mudanças em que se forja essa historicidade devemos inscrever a pesquisa no que ocorre sobre/na/pela cultura escolar, desde o ponto de vista do tempo e do espaço. A inclusão desses temas e das questões postas por eles oferece problemas conceituais, uma vez que não são simples esquemas abstratos ou estruturas neutras, assim como dificuldades na relação com as fontes; contudo, não deixam de abrir novos debates metodológicos.

Algumas pautas se apresentam para a (re)construção da categoria tempo escolar na pesquisa educativa. Entre elas destacamos: 1) o tempo de ensino, o qual engloba o tempo previsto por programas e o tempo dedicado à instrução e à educação que segue sob o controle da escola; 2) tempo de 
presença na escola, que estuda os tempos de recreio, de refeição, dos estudos; e 3) tempo das atividades educativas extra-escolares, as aulas de educação física, os trajetos de casa para escola, os deveres de casa e as aulas particulares (cf. COMPÈRE, 2000).

Uma questão que se apresenta a essas pautas diz respeito à atribuição de sentidos às fontes. Antes porque se exige ir mais além das normas prescritas nos textos ou registros oficiais, pois para o estudo da realidade média da escola há que ser fiel a uma dupla exigência: o rigor da diferenciação de categorias e a história, e a consideração da realidade em toda a sua complexidade para analisar os resultados obtidos.

Quanto à categoria espaço escolar, está fortemente associada na pesquisa histórico-educativa a idéia da arquitetura como programa (cf. ESCOLANO, 2000). Uma associação como essa remete à necessidade de se tomar o espaço como uma construção cultural que expressa e reflete, além de sua materialidade, determinados discursos. A (re)construção das imagens do espaço escolar, portanto, caracteriza pautas de pesquisas muito distintas que vão desde a perspectiva da microfísica da influência das estruturas arquitetônicas (FOUCAULT, 1982), passando por sua função simbólica e estética, até sua identificação como elemento do currículo oculto.

Na perspectiva da microfísica, o espaço escolar apresenta chaves de análises inseridas na tecnopolítica disciplinadora, a qual conta com dispositivos para fazer dóceis os corpos e as consciências. Quando se trata de sua função simbólica e estética, é possível apreender os espaços escolares dotados de dimensões semânticas, constituindo-se em referente de um modo de vida e civilização e de semiologias capazes de desconstruir e codificar elementos que expressam um sistema de intenções, valores e discursos que são próprios de determinada tradição cultural, por exemplo: os muros escolares, o pátio escolar, a separação arquitetônica das salas de aulas, etc.

Nessas pautas se inscrevem pesquisas que devem transcender os enfoques físicos, topográficos ou ecológicos do espaço escolar, voltandose para a busca de interpretações dos significados sociais e culturais, distanciando-se da idéia de neutralidade.

A consciência de que o tempo, o espaço e, enfim, a escola são determinados, acaba por afirmar que o diálogo com os objetos e fontes da pesquisa na/da cultura escolar deve estar orientado pela análise da educação escolar, nas sociedades, nas relações e nas disputas pelo capital cultural e, conseqüentemente, pelo reforço simbólico (reconhecimento e legitimação) das outras formas de capital. 
Uma importante contribuição para o estudo dessa afirmação é apresentada por Bourdieu (1999) na descrição de três conceitos, os quais conjuntamente podem referendar análises sobre o crescimento desmedido das características do primado da regra e do procedimento escrito e a formação de corpos especializados na interpretação das normas e dos rituais da cultura escolar, quais sejam: habitus, campo e práticas.

Para esse autor esses conceitos apresentam os seguintes conteúdos explicativos:

Habitus: mediação universalizante que faz com que as práticas sem razão explícitas e sem intenção significante de um agente singular sejam, no entanto "sensatas", "razoáveis" e objetivamente orquestradas;

Campo: noção que serve para indicar uma direção à pesquisa, definida negativamente como recusa à alternativa da interpretação interna e da explicação externa, perante a qual se achavam colocadas todas as ciências das obras culturais;

Práticas: produto da relação dialética entre uma situação e um habitus.

Independente do poder de nomeação e das representações que esses conceitos podem produzir, eles acabam por possibilitar o desocultamento das formas que orientam a organização dos alunos e dos professores e outros elementos que dão forma ao complexo processo de introduzir as gerações mais novas num sistema de valores que lhes precede. Dessa forma, a questão importante aqui não é o conteúdo desses conceitos, mas antes a forma que com eles a análise da cultura escolar pode assumir.

Se há algo que o uso desses três conceitos pode apresentar para esse objeto de pesquisa é a procura incessante pela apreensão da lógica da descontextualização das práticas, sua abstração e recontextualização no processo de tornarem-se material para serem analisadas e discutidas. $\mathrm{O}$ princípio básico dessa procura no lócus escola está na percepção de que as interações sociais não estão somente na forma como elas se apresentam à observação, mas no efeito do habitus, enquanto princípios geradores e organizadores de práticas e representações.

Essa fórmula, no entanto, parece estar sendo buscada por Pérez-Gomez (2001) ao estudar a escola como cruzamento de culturas, isto é, como instância de mediação cultural entre os significados, sentimentos e condutas da comunidade e o desenvolvimento das novas gerações. 
Para a elucidação desse cruzamento, detalha diferentes aspectos que compõem as culturas crítica, social, institucional e experiencial, que interagem no espaço escolar e cujo conhecimento auxilia a esclarecer o conjunto de fatores, muitas vezes imperceptíveis, que alimenta a cultura escolar.

Cabe aqui destacar os conceitos apresentados para cada uma das culturas que, segundo Pérez-Goméz (2001), estão em cruzamento:

CULTURA CRÍTICA - alta cultura ou cultura intelectual, o conjunto de significados e produções que, nos diferentes âmbitos do saber e do fazer, os grupos humanos foram acumulando ao longo da história;

CULTURA SOCIAL - conjunto de significados e comportamentos hegemônicos no contexto social, composto por valores, normas, idéias, instituições e comportamentos que dominam os intercâmbios humanos em sociedades formalmente democráticas, regidas pelas leis do livre mercado e percorridas e estruturadas pela onipresença dos poderosos meios de comunicação de massa;

CULTURA INSTITUCIONAL: as tradições, os costumes, as rotinas, os rituais e as inércias que a escola estimula e se esforça em conservar e reproduzir condicionam claramente o tipo de vida que nela se desenvolve e reforçam vigência de valores;

CULTURA EXPERIENCIAL: configuração de significados e comportamentos que os alunos e alunas elaboram de forma particular, induzido por seu contexto, em sua vida prévia e paralela à escola, mediante os intercâmbios "espontâneos" com os meios familiar e social que rodeiam a sua existência;

CULTURA ACADÊMICA: desde o currículo como transmissão de conteúdos disciplinares selecionados externamente à escola, desgarrados das disciplinas científicas e culturais, organizados em pacotes didáticos e oferecidos explicitamente de maneira prioritária e quase exclusiva pelos livros-didáticos, ao currículo como construção ad hoc e elaboração compartilhada no trabalho escolar por docentes e estudantes.

A identificação dessas culturas acaba por oferecer diferentes paradigmas de análises, seja do ponto de vista histórico ou sociológico. As experiências que se multiplicam sobre elas, ao mesmo tempo que ampliam ou fazem recuar as observações, proporcionam o encontro de novas/históricas ferramentas para refletir sobre os fenômenos, tornando disponíveis 
fontes/dados para comparação e difusão dos conceitos e dos métodos elaborados intra e extra-escola.

Para começar, podemos afirmar que a exploração das mudanças nas relações sociais que afetam as escolas compreendendo, por um lado, as subjetividades e identidades construídas por parte dos sujeitos que as habitam e as novas reconfigurações culturais que as estão envolvendo e, por outro lado, os discursos públicos construídos e as "narrativas sobrepostas" sobre a infância, os jovens, as agendas e os mandatos subjacentes, parecem ser percursos metodológicos inquestionáveis.

Em recente pesquisa desenvolvida, que teve como objetivo mapear as leituras e os leitores da escola inclusiva sul-mato-grossense, com atores definidos (professores e gestores), para compreender as novas reconfigurações culturais que estão a envolver a escola em tempos de inclusão, e perceber os discursos públicos construídos e "narrativas sobrepostas" sobre os alunos com necessidades especiais, encontramos na cultura escolar algumas formas mais arrojadas de interpretar a diferença na escola.

Se a partir dos resultados alcançados quisermos aprofundar, contando com as contribuições dos debates em torno das pautas de pesquisa em cultura escolar e, como temos vindo a afirmar, trazendo para dentro dela as subjetividades, assuntos e investimentos dos atores, professores, gestores e alunos com necessidades especiais na escola, deparamos com a necessária pergunta: quem são os atores que estão a construir a cultura escolar? Esta pergunta remete-nos para noções de espaço, tempo, discursos e (des)encontros culturais, não apenas de diferentes classes sociais, mas também de diferentes habitus e práticas.

Portanto, quando tomamos como objeto a cultura escolar não estamos essencializando a escola; antes, a estamos recolocando, no caso desta pesquisa, no centro das diferenças culturais e relações de poder. Como entendemos que a escola é não apenas um espaço de encontro, aceitação e contemplação das diferenças, antes de exploração e negociação de tensões, colocamos que as mudanças que estão a ocorrer, resultantes do confronto e da emergência dessa diversidade na escola e nas comunidades, precisam ser desocultadas.

Essa constatação faz com que percebamos que as possibilidades de pesquisa estão voltadas para a procura de caminhos no sentido da construção do próprio conceito de cultura, na perspectiva de que tome a solidez e a elasticidade capazes de abrigar a complexidade das práticas sociais e dos sentidos da escola. $\mathrm{O}$ último aspecto que nos parece conveniente comentar 
é a consistente produção brasileira de pesquisa na/da/sobre cultura escolar e, em especial, sua configuração no sentido de resgatar as culturas na escola e/ou ressignificar a cultura da escola.

Com relação às configurações acima citadas podemos apontar as áreas da História, História da Educação e das Ciências Sociais, em interface com o currículo, os estudos culturais, a literatura, o livro didático, o gênero, as políticas educacionais, entre outras, como aquelas que têm proporcionado pautas de investigação das/sobre manifestações concretas das formas pelas quais a escola lida com tais questões.

Enfim, mais do que buscar uma especificidade no conceito de cultura escolar, as idéias aqui reunidas pretenderam colocar em evidência e em debate várias formas pelas quais tal conceito pode ser (tem sido) pensado e articulado na pesquisa educacional.

\section{REFERÊNCIAS}

BERNSTEIN, Basil. A estruturação do discurso pedagógico: classe, códigos e controle. Tradução: Tomaz Tadeu da Silva e Luís Fernando Gonçalves Pereira. Petrópolis: Editora Vozes, 1996.

. Pedagogia, control simbólico e identidad. Madrid: Ediciones Morata, 1998.

BOURDIEU, Pierre. Contre-feux. Paris: Liber Raison D'agir, 1988.

. A dominação masculina. Rio de Janeiro: Bertrand Brasil, 1999.

Sistemas de enseñanza y sistemas de pensamiento. In: GIMENO SACRISTÁN, J.; PEREZ GOMEZ, A. La enseñanza: su teoria y su practica. Madrid: Akal, 1977.

; PASSERON, Jean Claude. A reprodução: elementos para uma teoria do sistema de ensino. 3. ed., Rio de Janeiro: Francisco Alves, 1992.

CANDIDO, Antonio. A estrutura da escola. In: PEREIRA, Luiz; FORACCHI, Marialice M. Educação e Sociedade. 6. ed. São Paulo: Editora Nacional, 1971.

Os parceiros do Rio Bonito. Rio de Janeiro: José Olympio, 1964.

COMPÈRE, Marie Madeleine. La historia del tiempo escolar en la Europa. In: BERRIO, Julio Ruiz (org). La cultura escolar de Europa. Madrid: Editorial Biblioteca Nueva, 2000.

CHERVEL, André. L'histoire des disciplines scolaires. Paris: Histoire de L'educacion, $\mathrm{n}$. 38, 1988, p. 59-119. 
SILVA, F. C. T. Cultura escolar: quadro conceitual e possibilidades de pesquisa

ESCOLANO, Augustin Benito. La historia de la educación después de la posmodernidad. In: BERRIO, Julio Ruiz (org). La cultura escolar de Europa. Madrid: Editorial Biblioteca Nueva, 2000.

FOCAULT, Michel. Microfísica do poder. Rio de Janeiro: Edições Graal, 1982.

FORQUIN, Jean-Claude. Escola e cultura: as bases sociais e epistemológicas do conhecimento escolar. Tradução: Guacira Lopes Louro. Porto Alegre: Artes Médicas, 1993.

HAMILTON, David. Mudança Social e mudança pedagógica: a trajetória de uma pesquisa histórica. Porto Alegre: Teoria e Educação, n. 6, 1992, p. 3-32.

JULIA, Dominique. A cultura escolar como objeto historiográfico. Tradução: Gizele de Souza. Revista Brasileira de História da Educação, São Paulo, n. 1, 2001, p. 9-44.

NÓVOA, Antonio (org.). As organizações escolares em análise. Lisboa: Nova Enciclopédia, 1998.

PERÉZ-GOMÉZ, A. I. A Cultura Escolar na sociedade neoliberal. Tradução: Ernani Rosa. Porto Alegre: Artmed Editora, 2001.

PINEAU, Pablo. Premisas básicas de la escolarización como construcción moderna que construyó a la modernidad. Revista de Estudios del Curriculum, Barcelona/Espanha, v. 2, n. 1, jan. 1999, p. 39-61.

SILVA, Fabiany de Cássia Tavares. As relações entre ensino, aprendizagem e deficiência mental desenhando a cultura escolar. São Paulo: PUC [Tese de Doutoramento], 2003.

VIÑAO FRAGO, Antonio. Culturas escolares, reformas e innovaciones: entre la tradición y el cambio. (texto divulgado pelo autor e ainda não publicado), 2000.

. El espacio y el tiempo escolares como objecto histórico. Contemporaneidade e Educação (Temas de História da Educação), Rio de Janeiro, Instituto de Estudos da Cultura Escolar, ano 5, n. 7, 2000 a.

. Tiempos escolares, tiempos sociales. Barcelona: Editorial Ariel Practicum, 1998.

WILLIAMS, R. Cultura. Rio de Janeiro: Editora Paz e Terra, 1992.

Texto recebido em 12 jun. 2005

Texto aprovado em 05 out. 2005 